\title{
Is it necessary to perform an endometrial sampling prior to hysterectomies for benign conditions?
}

\section{Erhan Hanligil, Mustafa Ayhan Ekici}

Department of Gynecology and Obstetrics, Bolu Abant Izzet Baysal University, Faculty of Medicine, Bolu, Turkey

\section{ABSTRACT}

Aim: Hysterectomy is one of the most prevalent surgical intervention in gynecological field. This study concerns the requirement and necessity of an endometrial sampling to exclude an unpredictable uterine malignancy risk before hysterectomy for benign conditions.

Methods: This is a retrospective and cross-sectional study involving 307 patients who had hysterectomy for benign conditions between years 2014-2018. Prior to hysterectomy, in 162 cases, an endometrial sampling was performed ahead (biopsy group) and in 145 cases, hysterectomy was performed without obtaining an endometrial sampling earlier on (control group). Pre- and postsurgical pathological evaluation reports were collected and compared between the groups.

Results: Features of the patients as mean age, number of previous pregnancies, being at postmenopausal status did not vary significantly between two groups. In the biopsy group, $51.2 \%$ of the patients were in the premenopausal period, $40.7 \%$ of the patients had postmenopausal bleeding and $52.5 \%$ had abnormal uterine bleeding symptoms and these three features were significantly higher than in the control group. In the control group, one case $(0.7 \%)$ had leiomyosarcoma and another case $(0.7 \%)$ had endometrial adenocarcinoma. In the biopsy group, endometrial adenocarcinoma was detected in 5 patients $(3.1 \%)$ as significantly higher than in the control group.

Conclusion: If there are no symptoms, clinical and radiological findings suggesting an endometrial malignancy in patients who planned to undergo a hysterectomy for benign conditions, it is unnecessary to perform a routine endometrial biopsy.

Keywords: Hysterectomy, endometrial biopsy, dilation and curettage, benign uterine conditions, endometrial malignancy.

Corresponding Author: Dr. Mustafa Ayhan Ekici, Department of Gynecology and Obstetrics, Bolu Abant Izzet Baysal University, Faculty of Medicine, Bolu, Turkey

Email:mayhanekici@hotmail.com ORCID ID: https://orcid.org/0000-0002-0745-0907
Received 2019-02-07, Revised 2019-03-04

Accepted 2019-03-09

Publication Date 2019-03-14 


\section{Introduction}

Hysterectomy is one of the most frequent surgical intervention of our field for the nonobstetric conditions. Endometriosis, chronic pelvic pain, pelvic inflammatory disease and uterine prolapses are the main benign indications for hysterectomy [1]. Performing an endometrial sampling prior to schedule a hysterectomy is regarded as a general consent in patients with suspicious history and findings for pre-malign disease and malignity of the endometrium [2-5]. It was reported that unexpected endometrial cancer and any other types of malignancies were incidentally found $0.12-2.7 \%$ and $0.19 \%$ respectively in hysterectomy specimens found in patients with benign preoperative indications [6]. For determining the type of surgical management and deployment, in some patients with uterine leiomyoma, endometrial sampling is applied to exclude a risk of underlying leiomyosarcoma [7].

In patients diagnosed with a pre-malign endometrial intraepithelial neoplasia by endometrial suction or curettage, endometrial carcinoma is found $40 \%$ in their hysterectomy specimens [8-10]. To reveal the cancer diagnosis in patients with abnormal uterine bleeding, dilatation and curettage (D\&C) is reported to be superior to any other endometrial sampling methods and for spaceoccupying lesions in the uterine cavity, a D\&C accompanied with hysteroscopy has been shown to be more sensitive [11,12]. Also, in patients with no lesions in the uterine cavity, $\mathrm{D} \& \mathrm{C}$ is the most precious diagnostic method to disclose endometrial premalignant lesions and any potentially underlying cancers [13].

We studied the necessity of endometrial sampling before performing hysterectomy for benign indications to avoid the risk of unpredictable uterine malignancy.

\section{Methods}

This study is a retrospective and crosssectional study which was conducted approving by the Clinical Research Ethics Committee of Bolu Abant Izzet Baysal University (document no: 78/2018). The survey consisted of 307 patients who were operated a hysterectomy in the Department of Gynecology and Obstetrics in Abant Izzet Baysal University between January 2014 and June 2018.

\section{Study Design}

The data of the patients enrolled in the study was collected from the records in the patient files and the hospital's automation software. The patients' main complaints for admitting for the outpatient clinic, age, and number of previous pregnancies, endometrial evaluation findings by transvaginal and / or abdominal ultrasonography, having periods or being at menopause status, results of endometrial D\&C pathology before hysterectomy, hysterectomy indications, hysterectomy methods, and pathology results of hysterectomy materials were studied.

The group with 162 patients who were undergone a D\&C before the hysterectomy was named as the "biopsy group" and the group with 145 patients who were made the hysterectomy without a D\&C was assigned as the "control group". The groups were collectively compared in terms of demographic aspects with their clinical and pathological findings between and within themselves.

The interpretation of endometrial evaluation by ultrasonography was made by measuring the endometrial double wall thickness by ultrasonographic endovaginal probe of Voluson Pro (General Electric, USA) and recorded in millimeters $(\mathrm{mm})$. In the postmenopausal patients, if the endometrium 
was thicker than $4 \mathrm{~mm}$, in existence of irregularity, identified lesion or fluid in the cavity, endometrial sampling was performed. For the premenopausal patients, if endometrial thickness was $>12 \mathrm{~mm}$, lesion or irregularity in the cavity were detected, and abnormal uterine bleeding history was determined, endometrial biopsy was applied. The procedure of endometrial sampling was performed by D\&C method under sedoanalgesia in all cases. The histological reporting of the benign endometrial biopsies were classified as proliferative endometrium, secretory endometrium, simple endometrial hyperplasia without atypia, endometrial polyp, chronic endometritis, atrophic endometrium, irregular proliferative endometrium, and inadequate material.

The term of indication of hysterectomy for a benign condition was assorted with diagnoses of leiomyoma uteri, abnormal uterine bleeding (AUB), simple endometrial hyperplasia without atypia, adenomyosis, pelvic inflammatory disease (PID), chronic pelvic pain (CPP), endometrial polyp (EP) and uterovaginal prolapse (UVP). Patients with endometrial hyperplasia with atypia and complex endometrial hyperplasia, endometrial intraepithelial neoplasia, cervical intraepithelial neoplasia (CIN) 2-3, ovarian tumors and pre-existing gynecological cancer, family history of gynecological malignancies, high blood levels of CA 125 and CA19-9 were not included in the study.

Types of hysterectomy in the study were recorded as laparoscopic hysterectomy, vaginal hysterectomy, and abdominal hysterectomy.

\section{Statistical analysis}

The analysis of the data was interpreted with the SPSS 23.00 program. Skewness-Kurtosis values were examined in the analysis for the normality test. The normality test of the scale was done to determine the test techniques to be used in the analysis and whether the distribution is normal. Since these values were between \pm 2 , it was accepted that normality for the values. Independent Samples t-test for comparison between 2 groups within the normal distribution of data, for the comparison of data that not distributed as normally, Mann-Whitney $U$ test for 2 groups and Kruskal-Wallis ANOVA test were used if there were over two groups. To analyze categorical variables, cross-tables were used and $\mathrm{p}<0.05$ value was regarded as significant for all analyses. Endometrial biopsy and pathology results were calculated as the number of patients and percentage.

\section{Results}

The biopsy group consisted of 162 patients and the control group consisted of 145 patients. Table 1 shows a comparison of demographic and clinical findings between the biopsy group and the control group. Mean Age, number of previous pregnancies (gravida), number of patients under the age of 40 and postmenopausal status did not differ significantly between the two groups (respectively; $p=0.916, p=0.395, p=0.125$, $p=0.125) .40 .7 \%$ of the patients in the biopsy group has symptoms of postmenopausal bleeding, and they were significantly higher than the control group $(p<0.001) .51 .2 \%$ of patients in the biopsy group had symptoms of abnormal uterine bleeding in the premenopausal period and $52.5 \%$ of them were significantly higher than the control group $(p<0.001, p<0.001)$.

Table 2 shows the indications of hysterectomy of biopsy and control groups. Within the hysterectomy indications in the control group, 
leiomyoma uteri $(37.9 \%)$ was the most common in the control group, abnormal uterine bleeding was the second $(22.8 \%)$ and uterovaginal prolapse was the third $(16.6 \%)$. Within the hysterectomy indications in the biopsy group: abnormal uterine bleeding $(52.5 \%)$ was the most common in the biopsy group, leiomyoma uteri was the second (28.4\%), and endometrial polyp (5.6\%) and uterovaginal prolapse $(5.6 \%)$ were the third.
Table 3 shows the pathology results of the biopsy group before the hysterectomy. While the endometrial polyp was found to be the most common with $42.6 \%$, it was determined secretory endometrium as $11.1 \%$, irregular proliferative endometrium as $9.3 \%$, atrophic endometrium as $8.6 \%$, proliferative endometrium as $8 \%$, endometrial hyperplasia as $6.8 \%$, and chronic endometritis as $1.2 \%$ and insufficient material as $12.3 \%$.

Table 1. Comparison of biopsy and control groups demographic and clinical findings.

\begin{tabular}{|l|l|l|l|}
\hline Parameters & $\begin{array}{l}\text { Biopsy group } \\
\mathbf{n = 1 6 2}\end{array}$ & $\begin{array}{l}\text { Control group } \\
\mathbf{n = 1 4 5}\end{array}$ & $\boldsymbol{p}$ \\
\hline Age (years) & $50.73+9.32$ & $50.84+9.41$ & 0.916 \\
\hline Gravidity (n) & $3.56+2.01$ & $3.37+2.02$ & 0.395 \\
\hline Endometrial thickness (mm) & $8,54+4.86$ & $5.92+4.86$ & $<0.001$ \\
\hline Postmenopausal patient (n) & 66 & 67 & 0.125 \\
\hline Premenopausal patient (> 40 age) (n) & 83 & 65 & $<0.001$ \\
\hline Postmenopausal bleeding (n) & 42 & 9 & $<0.001$ \\
\hline Abnormal uterine bleeding (n) & 85 & 33 & $<0.001$ \\
\hline Patients < 40 age (n) & 13 & 13 & 0.125 \\
\hline
\end{tabular}

The first 3 parameters are given as mean \pm standard deviation, others are given as numbers. $\mathrm{P}<0.05$ was regarded as significant.

Table 2. The indications of hysterectomy within control and biopsy groups.

\begin{tabular}{|c|c|c|c|c|c|c|c|c|c|}
\hline \multirow{2}{*}{\multicolumn{2}{|c|}{ Groups }} & \multicolumn{7}{|c|}{ Indication } & \multirow{3}{*}{\begin{tabular}{|l} 
Total \\
145
\end{tabular}} \\
\hline & & \multirow{2}{*}{$\frac{\mathbf{L U}}{55}$} & \multirow{2}{*}{\begin{tabular}{|l|}
$\mathbf{A U}$ \\
$\mathbf{K}$ \\
33 \\
\end{tabular}} & \multirow{2}{*}{$\begin{array}{l}\text { EP } \\
3 \\
\end{array}$} & \multirow{2}{*}{$\frac{\mathbf{U V P}}{24}$} & \multirow{2}{*}{\begin{tabular}{|l} 
CPP \\
12 \\
\end{tabular}} & \multirow{2}{*}{\begin{tabular}{|l} 
AD \\
1 \\
\end{tabular}} & \multirow{2}{*}{\begin{tabular}{|l|}
$\begin{array}{l}\text { Ovarian } \\
\text { Cyst }\end{array}$ \\
17 \\
\end{tabular}} & \\
\hline Control & Count & & & & & & & & \\
\hline Group & $\%$ & 37.9 & 22.8 & 2.1 & 16,6 & 8.3 & 0.7 & 11.7 & 100.0 \\
\hline Biopsy & Count & 46 & 85 & 9 & 9 & 4 & 3 & 6 & 162 \\
\hline Group & $\%$ & 28.4 & 52.5 & 5.6 & 5,6 & 2.5 & 1.9 & 3.7 & 100.0 \\
\hline \multirow{2}{*}{ Total } & Count & 101 & 118 & 12 & 33 & 16 & 4 & 23 & 307 \\
\hline & $\%$ & 32.9 & 38.4 & 3.9 & 10,7 & 5.2 & 1.3 & 7.5 & 100.0 \\
\hline
\end{tabular}

LU: Leiomyoma uteri, AUB: abnormal uterine bleeding, AD: adenomyosis, CPP:chronic pelvic pain, EP: endometrial polyp, UVP: uterovaginal prolapse. 
$152(49.5 \%)$ patients had abdominal, 128 $(41.7 \%)$ patients had total laparoscopic procedures and 27 patients $(8.8 \%)$ had vaginal hysterectomy.

Table 4 shows the distribution results of hysterectomy material pathology in two groups. One patient (0.7\%) had leiomyosarcoma in the control group and one patient $(0.7 \%)$ had endometrial endometrioid type of adenocarcinoma (e.e.adenoca). Five patients (3.1\%) had endometrium endometrioid type adeno carcinoma in the biopsy group and significantly higher than the control group $(\mathrm{p}<0.001)$.
The comparison of the results of endometrial biopsy pathology with results of hysterectomy material pathology is shown in Table 5. Two of the endometrial cancers were detected in patients with the endometrial polyp (40\%) preoperative biopsy, 1 (20\%) secretory endometrium, $1(20 \%)$ simple endometrial hyperplasia, and $1(20 \%)$ in those with insufficient material.

Endometrial cancer has mostly been reported in patients with the postmenopausal bleeding symptom $(80 \%)$.

Table 3. Preoperative pathology results in biopsy group.

\begin{tabular}{|c|c|c|c|c|c|c|c|c|c|c|}
\hline & \multicolumn{8}{|c|}{ Results of biopsy pathology } & \multirow[b]{2}{*}{ Total } \\
\hline & & 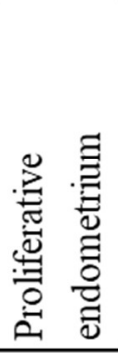 & 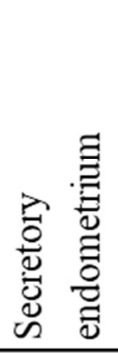 & 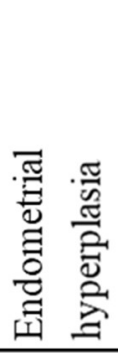 & 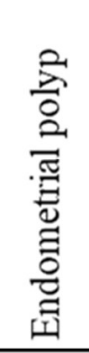 & 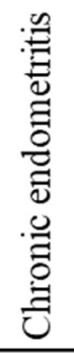 & 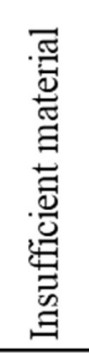 & 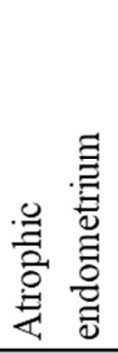 & 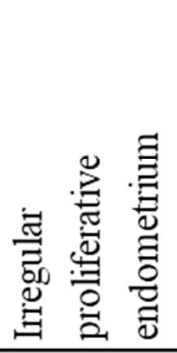 & \\
\hline \multirow[t]{2}{*}{ Biopsy Group } & Count & 13 & 18 & 11 & 69 & 2 & 20 & 14 & 15 & 162 \\
\hline & $\%$ & 8.0 & 11.1 & 6.8 & 42.6 & 1.2 & 12.3 & 8.6 & 9.3 & 100.0 \\
\hline
\end{tabular}

Table 4. Distribution of hysterectomy pathology results between groups.

\begin{tabular}{|c|c|c|c|c|c|c|c|c|c|c|c|}
\hline \multicolumn{12}{|c|}{ Group * Cross Tabulation of Pathology Report } \\
\hline & & \multicolumn{9}{|c|}{ Pathology Report } & \multirow[b]{2}{*}{ Total } \\
\hline & & 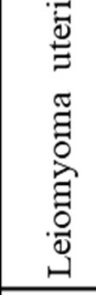 & 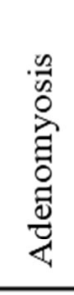 & 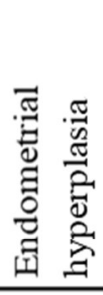 & 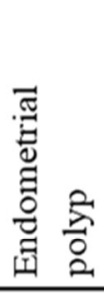 & 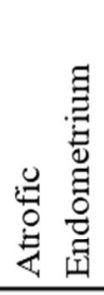 & 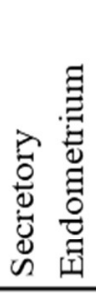 & 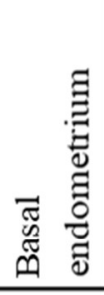 & 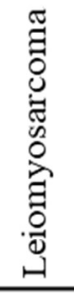 & 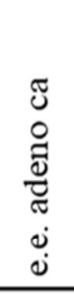 & \\
\hline \multirow{2}{*}{ Control Group } & Count & 70 & 30 & 4 & 9 & 16 & 14 & 0 & 1 & 1 & 145 \\
\hline & $\%$ & 48.3 & 20.7 & 2.8 & 6.2 & 11.0 & 9.7 & 0.0 & 0.7 & 0.7 & 100.0 \\
\hline \multirow{2}{*}{ Biopsy Group } & Count & 63 & 31 & 9 & 32 & 13 & 6 & 3 & 0 & 5 & 162 \\
\hline & $\%$ & 38.9 & 19.1 & 5.6 & 19.8 & 8.0 & 3.7 & 1.9 & 0.0 & 3.1 & 100.0 \\
\hline \multirow{2}{*}{ Total } & Count & 133 & 61 & 13 & 41 & 29 & 20 & 3 & 1 & 6 & 307 \\
\hline & $\%$ & 43.3 & 19.9 & 4.2 & 13.4 & 9.4 & 6.5 & 1.0 & 0.3 & 2.0 & 100.0 \\
\hline
\end{tabular}


Table 5. Cross-table of endometrial biopsy results and hysterectomy material pathology results in the biopsy group before hysterectomy.

\begin{tabular}{|c|c|c|c|c|c|c|c|c|c|c|}
\hline & & Patholog & eport* b & psy pre- & * Grou & Cross ? & abulatior & & & \\
\hline & & Biopsy p & & & & & & & & \\
\hline Material pathology hyst & rectomy & $\diamond \Xi$ & & & & & & & & Total \\
\hline Leiomyoma & Count & 9 & 10 & 4 & 22 & 2 & 5 & 3 & 8 & 63 \\
\hline & $\%$ & 14.3 & 15.9 & 6.3 & 34.9 & 3.2 & 7.9 & 4.8 & 12.7 & 100.0 \\
\hline Adenomyosis & Count & 4 & 4 & 1 & 10 & 0 & 6 & 3 & 3 & 31 \\
\hline & $\%$ & 12.9 & 12.9 & 3.2 & 32.3 & 0.0 & 19.4 & 9.7 & 9.7 & 100.0 \\
\hline Endometrial hyperplasia & Count & 0 & 0 & 5 & 2 & 0 & 2 & 0 & 0 & 9 \\
\hline & $\%$ & 0.0 & 0.0 & 55.6 & 22.2 & 0.0 & 22.2 & 0.0 & 0.0 & 100.0 \\
\hline Endometrial nolvn & Count & 0 & 0 & 0 & 29 & 0 & 1 & 1 & 1 & 32 \\
\hline & $\%$ & 0.0 & 0.0 & 0.0 & 90.6 & 0.0 & 3.1 & 3.1 & 3.1 & 100.0 \\
\hline Atrophic endometrium & Count & 0 & 0 & 0 & 1 & 0 & 5 & 7 & 0 & 13 \\
\hline & $\%$ & 0.0 & 0.0 & 0.0 & 7.7 & 0.0 & 38.5 & 53.8 & 0.0 & 100.0 \\
\hline Secretory endometrium & Count & 0 & 3 & 0 & 3 & 0 & 0 & 0 & 0 & 6 \\
\hline & $\%$ & 0.0 & 50.0 & 0.0 & 50.0 & 0.0 & 0.0 & 0.0 & 0.0 & 100.0 \\
\hline Basal endometrium & Count & 0 & 0 & 0 & 0 & 0 & 0 & 0 & 3 & 3 \\
\hline & $\%$ & 0.0 & 0.0 & 0.0 & 0.0 & 0.0 & 0.0 & 0.0 & 100.0 & 100.0 \\
\hline e.e. adenoca & \begin{tabular}{|l|} 
Count \\
\end{tabular} & 0 & 1 & 1 & 2 & 0 & 1 & 0 & 0 & 5 \\
\hline & $\%$ & 0.0 & 20.0 & 20.0 & 40.0 & 0.0 & 20.0 & 0.0 & 0.0 & 100.0 \\
\hline & \begin{tabular}{|l|} 
Count \\
\end{tabular} & 13 & 18 & 11 & 69 & 2 & 20 & 14 & 15 & 162 \\
\hline & $\%$ & 8.0 & 11.1 & 6.8 & 42.6 & 1.2 & 12.3 & 8.6 & 9.3 & 100.0 \\
\hline
\end{tabular}

\section{Discussion}

In our study, the incidence of unpredictable endometrial cancer was $0.7 \%$ in the control group, $3.1 \%$ in the biopsy group and $2 \%$ totally. The incidence of unpredictable leiomyosarcoma was $0.7 \%$ in the control group and $0.3 \%$ in the total. The incidence of unpredictable gynecological cancer was higher in studies with larger populations $[6,7,14]$. Ramm et al. $(n=708)$ detected cancer in five patients who were hysterectomized due to pelvic floor dysfunction. Among these five patients, two of them had an endometrial sampling, two had both endometrial sampling and ultrasonographic examination and one had only ultrasonographic examination for determining the underlying malignancy. In this study, they concluded that endometrial biopsy and ultrasonography should be performed before the surgery due to pelvic floor dysfunction [15]. In our study, patients who were detected a malignancy in the hysterectomy specimen were more common in the endometrial biopsy group and none were seen in those with pelvic floor dysfunction. Çelik et al. [3] $(n=200)$ found endometrial carcinoma after hysterectomy in one patient 
who was hysterectomized with the diagnosis of leiomyoma. They reported that endometrial sampling was necessary for patients with postmenopausal leiomyoma and that in patients with premenopausal should be decided according to the endometrial thickness. Kucur et al. [16] $(n=744)$ reported the greatest risk for endometrial carcinoma in patients with postmenopausal bleeding (5.6\%) and carried out that serious endometrial assessment and sampling should be performed in patients with postmenopausal bleeding. van Hanegem et al. [5] examined results of endometrial sampling of 12 studies involving 1029 women with postmenopausal bleeding, and it was found inadequate material in $11 \%$ of them and in $7 \%$ of them endometrial carcinoma was detected in their meta-analysis. It is more pointed out that the diagnosis study in women with postmenopausal bleeding should be done before hysterectomy. In our research, most of the patients with endometrial carcinoma were those with postmenopausal bleeding. In our study, $12.3 \%$ inadequate endometrial sampling was detected and one case with endometrial cancer was found among them. Yumuşak et al. [17] $(\mathrm{n}=198)$ reported that preoperative endometrial sampling had a low potential in patients with hysterectomy with benign preliminary diagnoses. Ercan et al. [18] (n = 332) reported that two patients presented with postoperative endometrial carcinoma in the presence of endometrial complex hyperplasia with atypia in the preoperative biopsy and that these patients had abnormal uterine bleeding and they concluded that routine endometrial sampling were unnecessary in patients with benign hysterectomy. Similarly, in our study, endometrial carcinoma has not been observed in patients without abnormal uterine bleeding. Hinchcliff et al. [19] $(n=329)$ reported that endometrial biopsy was inadequate in the diagnosis of uterine sarcoma. In our study, no sarcomas were found in the biopsy group. Only one case with leiomyosarcoma was seen in the control group.

The relatively low numbers of patients and the fact that the cases with abnormal uterine bleeding and postmenopausal bleeding cannot constitute a homogenous distribution among the groups may be mentioned as limitations of our study. An attentive endometrial examination for the patients who will have hysterectomy is already crucial but frankly, not all the patients need to have an endometrial sampling prior to surgery. Additionally, it must be kept in mind that, endometrial sampling may also skip a portion of endometrial malignancies as found in our biopsy group patients.

\section{Conclusion}

In patients who will scheduled for a hysterectomy secondary to benign gynecological disorders and conditions, there is no need for performing of routine a endometrial biopsy in absence of symptoms such as clinical, and radiological findings suggesting an endometrial malignancy. In patients with postmenopausal bleeding, although the result of preoperative endometrial sampling pathological examination is benign, it is useful that performing frozen section pathological examination of hysterectomy material during operation for a detailed and better attitude to exclude a potentially coexisting endometrial carcinoma.

Informed Consent: Informed consent was obtained from all individual participants included in the study.

Conflicts of interest: There are no conflicts of interest. 
Funding sources: This research did not receive any specific grant from funding agencies in the public, commercial, or not-forprofit sectors.

\section{References}

[1]ACOG Committee Opinion No. 444: choosing the route of hysterectomy for benign disease. Obstet Gynecol. 2009; 114 (5):1156-58.

[2]Reed SD, Newton KM, Clinton WL, Epplein M, Garcia R, Allison K et al. Incidence of endometrial hyperplasia. Am J Obstet Gynecol. 2009; 200(6):678.e1-6.

[3]Çelik Ö, Burak F, Atmaca R, Hasçalık Ş, Kafkaslı A. Uterin Fibromyomalı Kadınlarda Histerektomi Öncesi Endometrial Küretaj Gerekli Mi? Türkiye Klinikleri Jinekoloji-Obstetrik Dergisi 2001; 11: 365-68.

[4]İsgüder Ç, Doğru H, Özsoy Z, Çakmak B, Delibaş İ, Arıcı A, Demirtürk F. Histerektomi materyallerinde histopatolojik tanıların değerlendirilmesi. J Contemp Med. 2016;6(2): 87-91.

[5]van Hanegem N, Prins MMC, Bongers MY, Opmeer BC, Sahota DS, Mol BMJ, Timmermans A. The accuracy of endometrial sampling in women with postmenapozal bleeding: a systematic review and meta-analysis. Eur J Obstet Gynecol Reprod Biol. 2016; 197:147-55.

[6]Mahnert N, Morgan D, Campbell D, Johnston C, As-Sanie S. Unexpected gynecologic malignancy diagnosed after hysterectomy performed for benign indications. Obstet Gynecol. 2015; 125(2):397-405.

[7]Multinu F, Casarin J, Tortorella L, Huang $\mathrm{Y}$, Weaver A, Angioni S, et al. Incidence of sarcoma in patients undergoing hysterectomy for benign indications: a population-based study. Am J Obstet Gynecol. 2019; 220(2):179.e1-10.

[8]Mutter GL, Kauderer J, Baak JP, Alberts D; Gynecologic Oncology Group. Biopsy histomorphometry predicts uterine myoinvasion by endometrial carcinoma: a Gynecologic Oncology Group study. Hum Pathol. 2008; 39(6):866-74.

[9]Hecht JL, Ince TA, Baak JP, Baker HE, Ogden MW, Mutter GL. Prediction of endometrial carcinoma by subjective endometrial intraepithelial neoplasia diagnosis. Mod Pathol. 2005; 18(3):324-30.

[10] Trimble CL, Kauderer J, Zaino R, Silverberg S, Lim PC, Burke JJ, 2nd et al. Concurrent endometrial carcinoma in women with a biopsy diagnosis of atypical endometrial hyperplasia. A Gynecologic Oncology Group study. Cancer. 2006; 106(4): 812-19.

[11]Ben-Baruch G, Seidman DS, Schiff E, Moran O, Menczer J. Outpatient endometrial sampling with Pipelle curette. Gynecol Obstet Invest. 1994; 37(4): 26062.

[12]Leitao MM Jr, Han G Lee LX, Abu-Rustum NR, Brown CL, Chi DS et al. Complex atypical hyperplasia of the uterus: characteristics and prediction of underlying carcinoma risk. Am J Obstet Gynecol. 2010; 203(4): 349.e1-6.

[13]Bedner R, Rzepka-Gorska I. Hysteroscopy with directed biopsy versus dilatation and curettage for the diagnosis of endometrial hyperplasia and cancer in perimenapousal women. Eur J Gynaecol Oncol. 2007; 28(5): 400-2.

[14]Yuk JS, Kim LY, Kim SH, Lee JH. The incidence of unexpected uterine malignancy in women undergoing hysterectomy for a benign condition: a national population- 
Based study. Ann Surg Oncol. 2016; 23(12): 4029-34.

[15]Ramm O, Gleason JL, Segal S, Antosh DD, Kenton KS. Utility of preoperative endometrial assessment in asymptomatic women undergoing hysterectomy for pelvic floor dysfunction. Int Urogynecol J. 2012; 23(7):913-17.

[16]Kucur SK, Şencan H, Yüksel KB, Gözükara İ, Seven A, et al. Evaluation of endometrial biopsy in our clinic; analysis of 744 cases, Zeynep Kamil Tip Bülteni. 2014; 45(3):146-50.

[17] Yumuşak ÖH, Erkılınç S, Kahyaoğlu S, Erkaya S, Şenyurt H, et al. Evaluation of the diagnostic accuracy of endometrial sampling before hysterectomy. Jinekoloji Obstetrik ve Neonatoloji Tip Dergisi. 2014; 11(3): 97-100.

[18]Ercan Ö, Demir S, Dede FS. Benign nedenlerle yapılan histerektomi olgularında histerektomi öncesi endometrial örnekleme ve histerektomi sonrasi patoloji sonuçlarının karşılaştırılması. Ortadoğu Medical Journal. 2013; 5(4):190-93.

[19]Hinchcliff EM, Esselen KM, Watkins JC, Oduyebo T, Rauh-Hain JA, Del Carmen MG, et al. The role of endometrial biopsy in the preoperative detection of uterine leiomyosarcoma. J Minim Invasive Gynecol. 2016; 23(4): 567-72. 